\title{
Germinação de Sementes aéreas Pequenas de Trapoeraba (Commelina benghalensis)
}

\author{
Germination of Small Bengal Dayflower (Commelina benghalensis) Aerial Seeds
}

\author{
DIAS, A.C.R. ${ }^{2}$, CARVALHO, S.J.P. ${ }^{2}$, BRANCALION, P.H.S. ${ }^{2}$, NOVEMBRE, A.D.L.C. ${ }^{3} \mathbf{e}$ \\ CHRISTOFFOLETI, P.J. ${ }^{4}$
}

\begin{abstract}
RESUMO - O conhecimento científico sobre a biologia de plantas daninhas relacionado ao fluxo de emergência das plântulas, às causas de dormência das sementes e à profundidade máxima de emergência contribui significativamente para a utilização de estratégias racionais de manejo dessas plantas na agricultura. Assim, este trabalho foi desenvolvido com o objetivo de avaliar a germinação de sementes e a emergência da plântula de sementes aéreas pequenas de trapoeraba (Commelina benghalensis). Para isso, as sementes foram submetidas à superação de dormência em solução de ácido sulfúrico (por períodos de 1, 2, 3, 4 e 5 minutos), em diferentes condições de temperaturas (temperaturas médias de 16,1; 18,$6 ; 20,6 ; 23,1 ; 25,0 ; 26,9 ; 29,2 ; 31,1$; e 33,6 $\left.{ }^{\circ} \mathrm{C}\right)$, de luz (com e sem) e de profundidade de semeadura $(0,5,10,20,40$ e $80 \mathrm{~mm})$. A temperatura ótima para germinação da trapoeraba foi de $25^{\circ} \mathrm{C}$. Não houve efeito da luz na germinação das sementes. Não se observou interferência positiva na germinação por consequência do tratamento das sementes com ácido sulfúrico, em diferentes períodos de exposição, indicando que as sementes de trapoeraba não possuem impermeabilidade do tegumento à água. A emergência das plântulas de trapoeraba é influenciada negativamente e de forma linear pela profundidade de semeadura dos propágulos no substrato. Não houve emergência das plântulas quando as sementes foram depositadas a $80 \mathrm{~mm}$ de profundidade. $\mathrm{O}$ substrato areia favorece a emergência das plântulas.
\end{abstract}

Palavras-chave: temperatura, luz, dormência, emergência, biologia.

\begin{abstract}
Understanding basic information on weed biology related to plant emergence fluxes, seed dormancy causes and maximum depth for emergence may significantly contribute to creating rational strategies for weed management in agriculture. Thus, this work was developed to evaluate seed germination and seedling emergence of small aerial seeds of Bengal dayflower (Commelina benghalensis). Seeds were submitted to dormancy overcoming in sulfuric acid (periods of 1, 2, 3, 5 and 5 minutes) under different conditions of temperature (mean temperatures of 16.1; 18.6; 20.6; $23.1 ; 25.0 ; 26.9 ; 29.2 ; 31.1$ and $33.6^{\circ} \mathrm{C}$ ), light (with or without), and seeding depth in the substrate $(0,5,10,20,40$ and $80 \mathrm{~mm})$. The optimal temperature for Bengal dayflower germination was $25^{\circ} \mathrm{C}$. Light effects were not observed on seed germination. Positive consequences of seed treatment with sulfuric acid were not identified, considering different periods of exposure; indicating that Bengal dayflower seeds do not have tegument water impermeability. Seedling emergence is negative and linearly influenced by seeding depth in the substrate. Seedling emergence was not observed when seeds were $80 \mathrm{~mm}$ depth placed. Sand substrate favored seedling emergence.
\end{abstract}

Keywords: temperature, light, dormancy, emergence, biology.

Recebido para publicação em 11.8.2008 e na forma revisada em 11.12.2009.

2 Alunos de doutorado do Programa de Pós-Graduação em Fitotecnia da Escola Superior de Agricultura "Luiz de Queiroz" ESALQ/USP, <anacarolina.r.dias@gmail.com>, <sjpcarvalho@yahoo.com.br>, <pedrohsb@yahoo.com.br>; ${ }^{3}$ Professora Associada do Departamento de Produção Vegetal, ESALQ/USP, <adlcnove@esalq.usp.b>, Caixa Postal 09, 13419-900 Piracicaba-SP; ${ }^{4}$ Professor Associado do Dep. de Produção Vegetal, ESALQ/USP, <pjchrist@esalq.usp.br> 


\section{INTRODUÇÃO}

Entre as principais plantas daninhas infestantes das áreas agrícolas brasileiras, pode-se destacar a trapoeraba (Commelina benghalensis), por sua frequência de ocorrência e dificuldade de controle (Kissmann \& Groth, 1997). Em áreas onde o herbicida glyphosate é utilizado frequentemente, populações de C. benghalensis têm sido selecionadas, devido à tolerância da espécie às aplicações desse herbicida (Santos et al., 2001a; Monquero \& Christoffoleti, 2003; Rocha et al., 2007; Webster \& Grey, 2008), havendo a necessidade do desenvolvimento de alternativas de manejo, as quais, por sua vez, são dependentes de conhecimentos adicionais sobre a biologia da espécie. Dessa forma, o entendimento da germinação das sementes de espécies de plantas daninhas em relação aos fatores ambientais é importante para a interpretação do comportamento ecológico das espécies no campo, ao mesmo tempo que possibilita o desenvolvimento de estratégias de redução do potencial do banco de sementes em áreas cultivadas (Souza Filho, 2006).

A reprodução dessa espécie ocorre, geralmente, por sementes, mas pode haver a produção de rebentos a partir de gemas caulinares (Voll et al., 2002). A trapoeraba apresenta dois tipos de sementes: aéreas e subterrâneas fenômeno denominado de anficarpia. Estrategicamente, as sementes aéreas (alogâmicas) são produzidas pela planta daninha em ambientes cujos distúrbios não são previsíveis; portanto, a planta concentra energia para proporcionar rápida e abundante produção de sementes, apresentando flores na parte aérea. As sementes subterrâneas são formadas por cleistogamia (autopolinização), e a planta utiliza a estratégia de acumular grande quantidade de matéria seca antes de concentrar energia na produção de sementes, sendo esse comportamento devido à previsibilidade dos distúrbios ambientais (Webster \& Grey, 2008).

Tanto as sementes aéreas quanto as subterrâneas podem ser de dois tamanhos, motivo pelo qual são comumente denominadas de sementes aéreas grandes, sementes aéreas pequenas, sementes subterrâneas grandes e sementes subterrâneas pequenas (Maheshwari \& Maheshwari, 1955; Walker \& Evenson, 1985a;
Rodrigues, 1992; Gonzalez \& Haddad, 1995; Santos et al., 2001a). Segundo Walker \& Evenson (1985a), as sementes aéreas pequenas podem representar 73 a $79 \%$ do total de sementes produzidas; as sementes aéreas grandes, 19 a $22 \%$; e as subterrâneas, somente 1 a $3 \%$, o que faz com que as sementes aéreas pequenas sejam a principal forma de dispersão em áreas agrícolas.

A germinação é um processo biológico regulado por diversos fatores, dos quais a temperatura e a luz exercem influência significativa sobre ele. A temperatura afeta tanto a porcentagem final quanto a velocidade de germinação; além disso, ainda está relacionada com as reações bioquímicas necessárias para o início do processo germinativo (Carvalho $\&$ Nakagawa, 2000). Segundo Copeland \& McDonald (1985), a germinação será mais rápida e o processo mais eficiente quanto maior for a temperatura, dentro de certos limites. Dentro da faixa de temperatura em que as sementes de uma espécie germinam, existe uma temperatura ótima na qual ocorre o máximo de germinação em menor intervalo de tempo, sendo ela variável entre as espécies (Bewley \& Black, 1994). Conforme afirmaram Carvalho \& Nakagawa (2000), temperaturas inferiores ou superiores à ótima tendem a reduzir a velocidade do processo germinativo, expondo as plântulas por período maior aos fatores adversos, o que pode reduzir o total de germinação.

Vários autores têm estudado a temperatura mais adequada para a germinação de sementes de espécies de plantas daninhas. Por exemplo, foram definidas como ótimas as temperaturas de $30{ }^{\circ} \mathrm{C}$ para sementes de Sida rhombifolia (Cardoso, 1990); $25^{\circ} \mathrm{C}$ para as de Jacquinia brasiliensis (Garcia \& Lucas, 1994); $30{ }^{\circ} \mathrm{C}$ para as de Mimosa pudica e Ipomoea asarifolia (Souza Filho et al., 2001); $25^{\circ} \mathrm{C}$ para as de Paspalum maritimum (Souza Filho, 2006); e $20{ }^{\circ} \mathrm{C}$ para as de Conyza canadensis e Conyza bonariensis (Vidal et al., 2007).

Com relação à exigência de luz na germinação, há sementes que germinam apenas sob rápida exposição à luz e as que germinam após período amplo de exposição, sementes em que a germinação é desencadeada somente no escuro e, ainda, as indiferentes à luz (VázquezYanes \& Orozco-Segovia, 1991). Segundo 
Hilhorst \& Karssen (1988), a luz está ligada à ativação do sistema de fitocromos, o qual está relacionado ao funcionamento das membranas celulares, podendo ocasionar alteração no fluxo de inúmeras substâncias nas células e na permeabilidade das membranas, contribuindo assim para quebrar a dormência. Em espécies de plantas daninhas, têm sido realizados estudos para avaliar o efeito da condição de luz sobre a germinação. Em Sida cordifolia (Klein \& Felippe, 1991), Euphorbia hederifolia (Salvador, 2007) e Brachiaria plantaginea (Freitas et al., 1990; Salvador, 2007), constatou-se que as sementes germinaram independentemente da presença de luz.

O conhecimento de aspectos relacionados à emergência da plântula, às causas de dormência das sementes e à profundidade máxima na qual as plantas daninhas conseguem emergir permite a adoção das práticas adequadas de manejo, incluindo medidas culturais e não químicas (Brighenti et al., 2003; Souza Filho, 2006).

Este trabalho teve por objetivo avaliar a germinação da semente e a emergência das plântulas de sementes aéreas pequenas de trapoeraba (Commelina benghalensis) quando submetidas a diferentes temperaturas, condições de luz, superação de dormência e profundidade de semeadura.

\section{MATERIAL E MÉTODOS}

Quatro experimentos foram conduzidos na Escola Superior de Agricultura "Luiz de Queiroz", em Piracicaba-SP, em período compreendido entre agosto e dezembro de 2007. Os três primeiros experimentos, desenvolvidos no Laboratório de Análise de Sementes, estudaram a influência da temperatura e da luz e a escarificação química das sementes em solução de ácido sulfúrico para a germinação de sementes da trapoeraba. O quarto experimento foi desenvolvido em casa de vegetação, em que se avaliou a influência da profundidade de semeadura na emergência da plântula. Em todas as etapas foram utilizadas sementes aéreas pequenas de trapoeraba, adquiridas comercialmente da empresa Cosmos Agrícola Produção e Serviços Ltda. (Shokucho). As sementes foram armazenadas e posteriormente pesadas de acordo com
Santos et al. (2001b), que separam as sementes aéreas pequenas pela massa média de $1,90 \mathrm{mg}$ por semente. Não foram realizados testes preliminares de germinação com as sementes obtidas, devido à ausência de método padronizado para a condução do teste em trapoeraba.

\section{Influência da temperatura na germinação}

Visando à identificação da temperatura mais favorável para a germinação das sementes aéreas e pequenas de trapoeraba, foi instalado um experimento em mesa termogradiente na presença de luz, na qual se avaliou a germinação em nove faixas de temperaturas, compreendidas entre 15 e $35^{\circ} \mathrm{C}$ (temperaturas médias de 16,$1 ; 18,6 ; 20,6 ; 23,1$; 25,$0 ; 26,9 ; 29,2 ; 31,1$; e $\left.33,6{ }^{\circ} \mathrm{C}\right)$. O delineamento experimental foi o inteiramente casualizado, com quatro repetições, sendo cada faixa de temperatura considerada um tratamento.

Cada parcela constou de uma placa de Petri preenchida com areia, previamente peneirada, lavada e autoclavada a $200{ }^{\circ} \mathrm{C}$ por duas horas, onde foram semeadas 25 sementes de trapoeraba a $5 \mathrm{~mm}$ de profundidade. Antes da semeadura, o substrato foi umedecido com água destilada até atingir $60 \%$ de sua capacidade de retenção, sendo regularmente reumedecido. A partir do início do teste, a germinação foi avaliada diariamente até 24 dias após instalação (DAI), contando e retirando as sementes germinadas. Com os dados, foram calculados a germinação $(\mathrm{G} \%)$ e o indice de velocidade de germinação (IVG).

\section{Influência da luz na germinação}

$\mathrm{O}$ experimento foi conduzido em câmara de germinação tipo BOD, para avaliar a germinação das sementes de trapoeraba sob dois regimes de luz: branca contínua e escuro absoluto, ambos à temperatura de $25^{\circ} \mathrm{C}$. As unidades experimentais constaram de caixas plásticas $(0,11 \times 0,11 \times 0,03 \mathrm{~m})$ pretas (escuro) ou transparentes (luz), onde foram depositadas duas folhas de papel mata-borrão, umedecidas com quantidade de água equivalente a 2,3 vezes a massa do papel seco. Com base em ensaios prévios, essa proporção de água foi definida em razão do ponto de saturação do 
substrato, de forma que quantidades superiores de água adicionadas não foram absorvidas pelo papel. Em cada caixa plástica, foram distribuídas 50 sementes de trapoeraba. A porcentagem de germinação foi avaliada somente aos 10 DAI, contando-se o número de sementes germinadas, de modo a evitar a entrada de luz nas parcelas, o que poderia comprometer as avaliações. Em razão disso, neste trabalho, não foi possivel calcular o IVG. O delineamento experimental foi o inteiramente casualizado, com dois tratamentos (luz e escuro) e oito repetições.

\section{Influência da dormência na germinação}

O experimento foi desenvolvido para avaliar a escarificação química de sementes de trapoeraba em solução de ácido sulfúrico concentrado (98\%), durante 1, 2, 3, 4 e 5 minutos, acrescido de testemunha, sem imersão no ácido. Cada período de escarificação foi obtido por meio da imersão de amostras de sementes em um béquer de vidro, para depois ser adicionado o ácido sulfúrico em volume suficiente para permitir a completa imersão das sementes. Durante a escarificação, as soluções foram agitadas ocasionalmente. Transcorrido o tempo estipulado, o excesso de ácido foi retirado do béquer e as sementes foram despejadas em um balde com 20 L de água. Primeiramente, realizou-se a escarificação das sementes por um minuto, depois se procedeu à escarificação de outra amostra de sementes por dois minutos, e assim sucessivamente, até que os cinco periodos de escarificação química fossem obtidos. Posteriormente, as sementes foram lavadas em água corrente e secadas à sombra. Após secagem das sementes em temperatura ambiente por uma hora, instalou-se o teste de germinação em câmara do tipo BOD, com temperatura de $25^{\circ} \mathrm{C}$.

As unidades experimentais constaram de caixas plásticas transparentes $(0,11 \times 0,11 \mathrm{x}$ $0,03 \mathrm{~m}$ ), onde foram depositadas duas folhas de papel mata-borrão, umedecidas com quantidade de água equivalente a 2,3 vezes a massa do papel seco. Em cada parcela, foram distribuídas 50 sementes de trapoeraba. A partir do início do teste, a germinação foi avaliada diariamente até 24 dias após instalação (DAI), contando e retirando as sementes germinadas.
Com os dados, foram calculados a germinação $(G \%)$ e o indice de velocidade de germinação (IVG). O delineamento experimental foi o inteiramente casualizado, com seis tratamentos e quatro repetições.

\section{Influência da profundidade da semeadura $e$ do substrato na emergência de plântulas}

O experimento foi conduzido com delineamento experimental em blocos ao acaso com quatro repetições no esquema fatorial $3 \times 6$, em que três foram os substratos (solo francoargiloarenoso, solo franco-arenoso e areia pura) e seis foram as profundidades de semeadura $(0,5,10,20,40$ e $80 \mathrm{~mm})$. A análise química e física dos solos utilizados no experimento encontra-se na Tabela 1. As parcelas constaram de vasos plásticos com capacidade para 1,5 L, preenchidos com os substratos e acrescidos de 0,20 g de sementes de trapoeraba, distribuídas nas profundidades predeterminadas. A avaliação das plântulas emersas foi realizada aos 14 e aos 28 DAI, somando-se, posteriormente, o número total acumulado de plântulas emersas.

\section{Avaliações e análise estatística}

Em todos os trabalhos desenvolvidos em laboratório, a avaliação da germinação foi realizada conforme as Regras para Análise de Sementes (Brasil, 1992), considerando-se como plântulas normais as que possuíam todas as estruturas essenciais do embrião desenvolvidas.

O IVG foi calculado pela fórmula proposta por Maguire (1962):

$$
I V G=\sum\left(\frac{N S G}{D A I}\right)
$$

em que NSG: número não acumulado de sementes germinadas por 100 sementes e DAI: dias após instalação do teste.

Todos os dados foram submetidos à aplicação do teste $\mathrm{F}$ na análise da variância. Quando se identificou efeito de niveis de tratamentos, as médias foram comparadas pelo teste de Tukey a $5 \%$ de probabilidade ou por regressões polinomiais. O procedimento estatístico foi adotado em adequação ao principal objetivo de 
Tabela 1 - Propriedades químicas e físicas ${ }^{1 /}$ dos solos utilizados no experimento de profundidade de semeadura de sementes de trapoeraba. Piracicaba-SP, 2007

\begin{tabular}{|c|c|c|c|c|c|c|c|c|c|c|}
\hline \multicolumn{11}{|c|}{ Propriedades químicas } \\
\hline \multirow[t]{2}{*}{ Solo } & $\mathrm{pH}$ & $\begin{array}{l}\text { Matéria } \\
\text { orgânica }\end{array}$ & $\mathrm{P}$ resina & $\mathrm{K}$ & $\mathrm{Ca}$ & $\mathrm{Mg}$ & $\mathrm{Al}$ & CTC & $\mathrm{V}$ & M \\
\hline & $\left(\mathrm{CaCl}_{2}\right)$ & $\left(\mathrm{g} \mathrm{dm}^{-3}\right)$ & $\left(\mathrm{mg} \mathrm{dm}^{-3}\right)$ & \multicolumn{5}{|c|}{$\left(\mathrm{mmol}_{\mathrm{c}} \mathrm{dm}^{-3}\right)$} & \multicolumn{2}{|c|}{$(\%)$} \\
\hline Franco-argiloarenoso & 5,2 & 65 & 99 & 19,4 & 68 & 25 & 2 & 154 & 73 & 2 \\
\hline Franco-arenoso & 4,4 & 9 & 3 & 0,5 & 12 & 5 & 2 & 40 & 44 & 10 \\
\hline \multicolumn{11}{|c|}{ Propriedades físicas } \\
\hline \multirow{3}{*}{ Solo } & \multicolumn{2}{|c|}{ Argila } & \multicolumn{2}{|c|}{ Silte } & \multirow{2}{*}{ Areia Total } & \multicolumn{3}{|c|}{ Areia Grossa } & \multicolumn{2}{|c|}{ Areia Fina } \\
\hline & \multicolumn{2}{|c|}{$<0,002 \mathrm{~mm}$} & \multicolumn{2}{|c|}{$0,053-0,002 \mathrm{~mm}$} & & \multicolumn{3}{|c|}{$2,00-0,210 \mathrm{~mm}$} & \multicolumn{2}{|c|}{$0,210-0,053 \mathrm{~mm}$} \\
\hline & \multicolumn{10}{|c|}{$\left(\mathrm{g} \mathrm{kg}^{-1}\right)$} \\
\hline Franco-argiloarenoso & \multicolumn{2}{|c|}{293} & \multicolumn{2}{|c|}{247} & 460 & \multicolumn{3}{|c|}{220} & \multicolumn{2}{|c|}{240} \\
\hline Franco-arenoso & \multicolumn{2}{|c|}{203} & \multicolumn{2}{|c|}{180} & 779 & \multicolumn{3}{|c|}{310} & \multicolumn{2}{|c|}{469} \\
\hline
\end{tabular}

1/ Análise realizada por PIRASOLO Laboratório Agrotécnico Piracicaba Ltda.

cada experimento, visando à interpolação de pontos (experimento com diferentes temperaturas e profundidades) ou comparação direta com a testemunha (escarificação).

\section{RESULTADOS E DISCUSSÃO}

No primeiro experimento, a aplicação do teste $\mathrm{F}$ na análise da variância indicou significância dos niveis de tratamentos (temperaturas), justificando a adoção de regressões polinomiais. Para a variável germinação $(\% \mathrm{G})$, os dados foram ajustados à regressão polinomial de terceiro grau (Figura 1A), cujo ponto máximo, obtido matematicamente, correspondeu à temperatura de $23,38^{\circ} \mathrm{C}$. Quanto ao indice de velocidade de germinação (IVG), os dados foram ajustados à regressão polinomial de segundo grau, cujo ponto máximo obtido foi correspondente à temperatura de $26,1{ }^{\circ} \mathrm{C}$ (Figura 1B). Considerando-se, concomitantemente, a resposta das duas variáveis para obtenção da temperatura ideal, tem-se média de $24,74^{\circ} \mathrm{C}$, o que, em termos laboratoriais, é pouco prático. Assim, julgou-se como sendo $25{ }^{\circ} \mathrm{C}$ a temperatura que proporciona melhor resposta germinativa da trapoeraba. Ainda, as temperaturas médias de 31,34 e $19{ }^{\circ} \mathrm{C}$ proporcionaram baixa $\% \mathrm{G}$, porém foram superiores às temperaturas de $16^{\circ} \mathrm{C}$, em que se obteve a menor \%G e IVG entre as temperaturas estudadas (Figura 1).

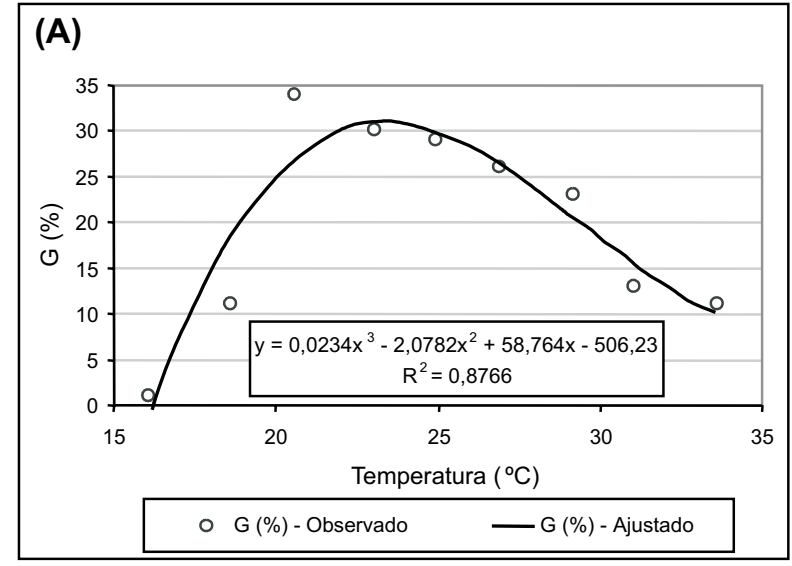

(B)

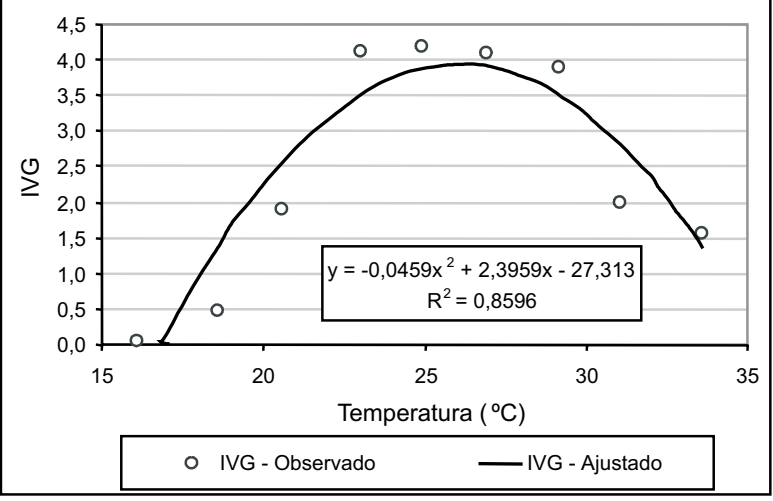

Figura 1 - Germinação (G\% - A) e índice de velocidade de germinação (IVG - B) de sementes de trapoeraba (Commelina benghalensis) submetidas a nove intervalos de temperatura. Piracicaba-SP, 2007. 
Resultados semelhantes foram encontrados por Santos et al. (2001b), que chegaram ao intervalo de $20-35^{\circ} \mathrm{C}$; por Walker \& Everson (1985a), trabalhando com uma população de sementes originárias da Austrália, que obtiveram as maiores porcentagens de germinação a 24 e $28{ }^{\circ} \mathrm{C}$; e por Gonzalez \& Haddad (1995), com uma população de sementes originárias de ou coletadas em Campinas-SP, que indicaram que as temperaturas ótimas foram $25 \mathrm{e}$ $30{ }^{\circ} \mathrm{C}$.

No segundo experimento, não foram observadas diferenças de germinação quando as sementes de trapoeraba foram submetidas às condições de luz contínua e escuro absoluto a $25^{\circ} \mathrm{C}$ (Tabela 2). Portanto, constatou-se ausência de efeitos da luz na germinação dessas sementes, que podem ser classificadas como fotoblásticas indiferentes. Gonzalez \& Haddad (1995) também concluíram que as sementes germinaram tanto em condições de luz como de escuro. Contudo, Walker \& Everson (1985a) relataram que a exposição à luz aumentou a germinação das sementes aéreas e pequenas.

No terceiro experimento, nenhum dos tratamentos com exposição das sementes ao ácido sulfúrico apresentou incremento na \%G e no IVG (Tabela 3). As sementes não escarificadas (testemunha) não diferiram das expostas ao ácido por um e dois minutos. A escarificação das sementes, com exposições ao ácido por três, quatro ou cinco minutos, diminuiu a \%G e o IVG. Esses dados divergiram daqueles obtidos por Kim et al. (1990), que constataram significativo aumento na porcentagem de germinação com o tratamento com ácido sulfúrico concentrado; e por Rodrigues \& Pitelli (1994), os quais concluíram que o

Tabela 2 - Germinação (\%) de sementes de trapoeraba (Commelina benghalensis) em condição de luz e escuro, sob temperatura constante de $25^{\circ} \mathrm{C}$. Piracicaba-SP, 2007

\begin{tabular}{|l|c|}
\hline \multicolumn{1}{|c|}{ Luz } & Germinação (\%) \\
\hline Ausência de luz & 30,25 \\
\hline Presença de luz & 33,75 \\
\hline $\mathrm{F}_{\text {(Trat.) }}$ & $1,65^{\mathrm{NS}}$ \\
\hline $\mathrm{DMS}$ & 5,84 \\
\hline CV (\%) & 17,01 \\
\hline
\end{tabular}

$\mathrm{NS}=$ não significativo pelo teste $\mathrm{F}$ a $5 \%$ de probabilidade
Tabela 3 - Germinação (\%G) e índice de velocidade de germinação (IVG) de sementes de trapoeraba (Commelina benghalensis) submetidas a seis períodos de exposição ao ácido sulfúrico. Piracicaba-SP, 2007

\begin{tabular}{|c|c|c|}
\hline Exposição (minutos) & $\% \mathrm{G}$ & IVG \\
\hline 0 & $45,5 \mathrm{a}$ & $3,77 \mathrm{a}$ \\
\hline 1 & $45,0 \mathrm{a}$ & $3,92 \mathrm{a}$ \\
\hline 2 & $44,5 \mathrm{a}$ & $3,99 \mathrm{a}$ \\
\hline 3 & $14,5 \mathrm{~b}$ & $1,32 \mathrm{~b}$ \\
\hline 4 & $6,0 \mathrm{~b}$ & $0,52 \mathrm{~b}$ \\
\hline 5 & $6,5 \mathrm{~b}$ & $0,57 \mathrm{~b}$ \\
\hline $\mathrm{DMS}$ & 9,82 & 0,83 \\
\hline $\mathrm{CV}$ & 16,19 & 15,68 \\
\hline
\end{tabular}

Médias acompanhadas de letras iguais não diferem pelo teste de Tukey a 5\% de significância.

tratamento com ácido sulfúrico concentrado foi o método de superação de dormência que proporcionou as maiores porcentagens de germinação em todas as classes ou tipos de sementes estudados; estes autores também observaram que as sementes áreas e pequenas foram as que tiveram as porcentagens de germinação significativamente menores que as demais quando tratadas por dois minutos com ácido sulfúrico.

Em geral, tem-se observado variabilidade de alguns dados sobre a germinação de sementes de trapoeraba, publicados em trabalhos nacionais e internacionais. Por exemplo, Walker \& Evenson (1985b) encontraram diferenças de germinação entre sementes grandes e pequenas, dependendo da sua origem, bem como em função do ano de produção ou, então, devido aos diferentes efeitos dos fatores que promoveram a sua germinação (temperatura, luz). Santos et al. (2001b) também observaram diferenças no grau de dormência entre os tipos de sementes de C. benghalensis e concluíram que a produção de sementes polimórficas com diferenças no grau de dormência permite que aquelas dessa espécie germinem e se estabeleçam nos mais diversificados ambientes e em diferentes épocas do ano, o que dificulta o manejo dessa planta daninha.

No quarto experimento, quanto ao efeito de profundidade de semeadura, a análise da variância indicou interação significativa da 
profundidade e do tipo de substrato. Para os três substratos, os dados foram adequadamente ajustados às regressões lineares, comprovando que a profundidade de semeadura no solo influencia negativamente a emergência das plântulas, impedindo-lhes a emergência a $80 \mathrm{~mm}$ de profundidade (Tabela 4). Isso indica que o posicionamento das sementes a mais de $80 \mathrm{~mm}$ de profundidade pode funcionar como método cultural para o manejo da espécie. Ainda, foi observado maior número de plântulas emersas em areia pura quando comparada com os demais substratos (Figura 2), demonstrando ser este o melhor substrato.

Tabela 4 - Análise de regressão e seus parâmetros para relação entre a emergência de plântulas de trapoeraba (Commelina benghalensis) e a profundidade das sementes em três substratos diferentes. Piracicaba-SP, 2007

\begin{tabular}{|l|c|c|c|}
\hline \multicolumn{4}{|c|}{ Equação linear de primeiro grau: $\mathrm{y}=\mathrm{ax}+\mathrm{b}$} \\
\hline \multirow{2}{*}{ Substrato } & \multicolumn{3}{c|}{ Parâmetro } \\
\cline { 2 - 4 } & $\mathrm{a}$ & $\mathrm{b}$ & $\mathrm{R}^{2}$ \\
\hline Solo franco-arenoso & $-0,3384$ & 25,4930 & 0,9404 \\
\hline Solo franco-argiloarenoso & $-0,2517$ & 20,8360 & 0,9694 \\
\hline Areia pura & $-0,7083$ & 56,2570 & 0,9642 \\
\hline
\end{tabular}

Os resultados obtidos assemelham-se aos apresentados por Fausey \& Renner (1997), Brighenti et al. (2003) e Muniz Filho et al. (2004), que estudaram a germinação de sementes de outras espécies de plantas daninhas, como Setaria faberi e Panicum dichotomiflorum, Cardiospermum halicacabum e Bidens pilosa, respectivamente. Também observaram que a maior porcentagem de germinação ocorreu quando as sementes foram posicionadas entre 10 e $50 \mathrm{~mm}$ de profundidade, embora possa haver germinação em profundidades de até $120 \mathrm{~mm}$.

Segundo Canossa et al. (2007), muitas espécies de plantas daninhas, sobretudo as que possuem sementes com poucas reservas, germinam quando dispostas em pequenas profundidades no solo, pois essas sementes, em sua maioria, necessitam do estimulo luminoso. Uma vez que a luz é fortemente atenuada, à medida que a profundidade no solo aumenta, normalmente sementes dessas espécies, quando colocadas em maiores profundidades, não são capazes de emergir. No entanto, há espécies que não necessitam do estímulo luminoso para dar início ao processo de germinação (como foi o caso da trapoeraba

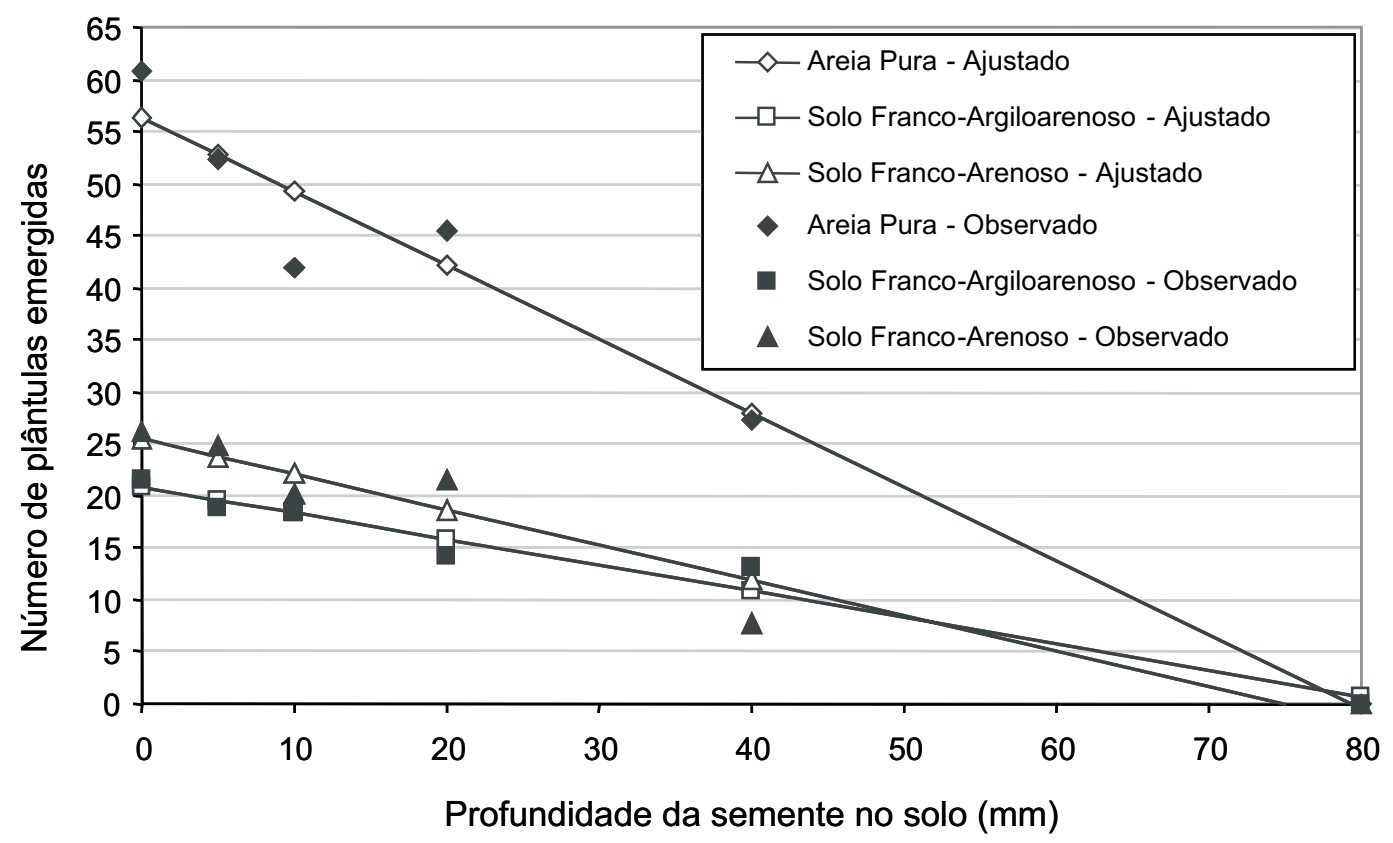

Figura 2 - Emergência de plântulas de trapoeraba (Commelina benghalensis) em função da profundidade da semente em três substratos diferentes. DMS ${ }_{\text {solo }}=12,85$. Piracicaba-SP, 2007. 
neste trabalho) e que podem, portanto, emergir a partir de maiores profundidades, até o máximo de interferência do efeito físico de impedimento ou de redução da temperatura.

Assim, com o desenvolvimento deste trabalho, pôde-se concluir que a temperatura ótima para germinação da trapoeraba foi de $25^{\circ} \mathrm{C}$. Não houve efeito da luz na germinação das sementes. Não se observou interferência positiva na germinação por consequência do tratamento das sementes com ácido sulfúrico em diferentes períodos de exposição, indicando que as sementes de trapoeraba não possuem impermeabilidade do tegumento à água. A emergência das plântulas de trapoeraba é influenciada negativamente e de forma linear pela profundidade de semeadura dos propágulos no substrato. Não houve emergência das plântulas quando as sementes foram depositadas a $80 \mathrm{~mm}$ de profundidade. O substrato areia favorece a emergência das plântulas.

\section{AGRADECIMENTOS}

À Coordenação de Aperfeiçoamento de Pessoal de Nivel Superior (CAPES), pela bolsa de mestrado concedida ao primeiro autor, e a todos que colaboraram para a realização deste trabalho.

\section{LITERATURA CITADA}

BEWLEY, J. D.; BLACK, M. Some ecophysiological aspects of germination In: BEWLEY, J. D.; BLACK, M. Seeds: physiology of development and germination. 2.ed. New York: Plenum Press, 1994. p. 237-252.

BRASIL. Ministério da Agricultura e Reforma Agrária. Coordenação de Laboratório Vegetal. Regras para análise de sementes. Brasília: 1992. 365 p.

BRIGHENTI, A. M.; VOLL, E.; GAZZIERO, D. L. P. Biologia e manejo do Cardiospermum halicacabum. Planta Daninha, v. 21, n. 2, p. 229-237, 2003.

CANOSSA, R. S. et al. Profundidade de semeadura afetando a emergência de plântulas de Alternanthera tenella.

Planta Daninha, v. 25, n. 4, p. 719-725, 2007.

CARDOSO, V. J. M. Germination studies on dispersal units of Sida rhombifolia L. R. Bras. Bot., v. 13, n. 1, p. 83-88, 1990.

CARVALHO, N. M.; NAKAGAWA, J. Sementes: ciência, tecnologia e produção. 4.ed. Jaboticabal: Funep, 2000. 588 p.
COPELAND, L. O.; McDONALD, M. B. Principles of seed science and technology. 2.ed. Minneapolis: Burgess Publishing Company, 1985. 312 p.

FAUSEY, J. C.; RENNER, K. A. Germination, emergence, and growth of giant foxtail (Setaria faberi) and fall Panicum (Panicum dichotomiflorum). Weed Sci., v. 45, n. 3, p. 423-425, 1997.

FREITAS, R. R.; CARVALHO, D. A.; ALVARENGA, A. A Quebra de dormência e germinação de sementes de capimmarmelada [Brachiaria plantaginea (Link) Hitch]. R. Bras. Fisiol. Veg., v. 2, n. 2, p. 31-35, 1990.

GARCIA, Q. S.; LUCAS, N. M. C. Germinative behaviour of Jacquinia brasiliensis seeds. R. Bras. Bot., v. 17, n. 1, p. 13-18, 1994

GONZALEZ, C. B.; HADDAD, C. R. B. Efeito da luz e temperatura na floração e germinação de sementes de Commelina benghalensis L. Arq. Biol. Tecnol., v. 38, n. 2, p. 651-659, 1995.

HILHORST, H. W. M.; KARSSEN, C. M. Dual effects of light on the gibberelin and nitrate- stimulated seed germination of Sisymbrium officinale and Arabidopsis thaliana. Plant Physiol., v. 86, n. 3, p. 591-597, 1988.

KIM, S. Y; DEDATTA, S. K.; MERCADO, B. L. The effect of chemical and heat treatments on germination of Commelina benghalensis L. aerial seeds. Weed Res., v. 30, n. 2 , p. 109-116, 1990.

KISSMANN, K. G.; GROTH, D. Plantas infestantes e nocivas. 2.ed. São Paulo: BASF, 1997. Tomo I. 825 p.

KLEIN, A.; FELIPPE, G. M. Efeito da luz na germinação de sementes de ervas invasoras. Pesq. Agropec. Bras., v. 26, n. 7, p. 955-966, 1991.

MAGUIRE, J. D. Speed of germination-aid in selection and evaluation for seedling emergence vigor. Crop Sci., v. 2, n. 2, p. 176-177, 1962.

MAHESHWARI, P.; MAHESHWARI, J. K. Floral dimorphism in Commelina forskalaei Vahl and $C$. benghalensis L. Phytomorphology, v. 5, n. 4, p. 413-422, 1955.

MONQUERO, P. A.; CHRISTOFFOLETI, P. J. Dinâmica do banco de sementes em áreas com aplicação freqüente do herbicida glyphosate. Planta Daninha, v. 21, n. 1, p. 63-69, 2003.

MUNIZ FILHO, A. et al. Capacidade de emergência de picãopreto em diferentes profundidades de semeadura. R. Biol. Ci. Terra, v. 4, n. 1, 2004. 
ROCHA, D. C.; RODELLA, R. A.; MARTINS, D. Caracterização morfológica de espécies de trapoeraba (Commelina spp.) utilizando a análise multivariada.

Planta Daninha, v. 25, n. 4, p. 671-678, 2007.

RODRIGUES, B. N. Estudos sobre a dormência, crescimento, absorção de macronutrientes e resposta à calagem por C. benghalensis L. 1992. 129 f. Tese (Doutorado em Produção Vegetal) - Universidade Estadual Paulista "Júlio de Mesquita Filho", Jaboticabal, 1992.

RODRIGUES, B. N.; PITELLI, R. A. Quebra de dormência em sementes de Commelina benghalensis. Planta Daninha, v. 12, n. 2, p. 106-110, 1994.

SALVADOR, F. L. Germinação e emergência de plantas daninhas em função da luz e da palha de cana-de-açúcar (Saccharum spp.). 2007. 84 f. Dissertação (Mestrado em Fitotecnia) - Escola Superior de Agricultura "Luiz de Queiroz", Universidade de São Paulo, Piracicaba, 2007.

SANTOS, I. C. et al. Eficiência do herbicida glyphosate no controle de Commelina benghalensis e Commelina diffusa. Planta Daninha, v. 19, n. 1, p. 135-143, 2001a.

SANTOS, I. C. et al. Germinação de sementes aéreas e subterrâneas de Commelina benghalensis. Planta Daninha, v. 19, n. 2, p. 163-170, 2001 b.

SOUZA FILHO, A. P. S. et al. Germinação de sementes de plantas daninhas de pastagens cultivadas: Mimosa pudica e Ipomoea asarifolia. Planta Daninha, v. 19, n. 1, p. 23-31, 2001.
SOUZA FILHO, A. P. S. Interferência potencialmente alelopática do capim-gengibre (Paspalum maritimum) em áreas de pastagens cultivadas. Planta Daninha, v. 24, n. 3, p. 451-456, 2006.

VÁZQUEZ-YANES, C.; OROZCO-SEGOVIA, A. Seed viability, longevity and dormancy in a tropical rain forest. In: SIMPÓSIO BRASILEIRO SOBRE TECNOLOGIA DE SEMENTES FLORESTAIS, 2., 1991, São Paulo. Anais... São Paulo: Instituto Florestal, 1991. p. 175-196.

VIDAL, R. A. et al. Impacto da temperatura, irradiância e profundidade das sementes na emergência e germinação de Conyza bonariensis e Conyza canadensis resistentes ao glyphosate. Planta Daninha, v. 25, n. 2, p. 309-315, 2007.

VOLL, E. et al. Aspectos fisiológicos da germinação de sementes de trapoeraba (Commelina benghalensis L.). R. Bras. Sementes, v. 24, n. 1, p. 162-168, 2002.

WALKER, S. R.; EVENSON, J. P. Biology of Commelina benghalensis L. in south-eastern Queensland. 1. Growth, development and seed production. Weed Res., v. 25, n. 4. p. 239-244, 1985a.

WALKER, S. R.; EVENSON, J. P. Biology of Commelina benghalensis L. in south-eastern Queensland. 2. Seed dormancy, germination and emergence. Weed Res., v. 25, n. 4, p. $245-250,1985 b$.

WEBSTER, T. M.; GREY, T. L. Growth and reproduction ofbBengal dayflower (Commelina benghalensis) in response to drought stress. Weed Sci., v. 56, n. 4, p. 561-566, 2008. 